Provided for non-commercial research and education use. Not for reproduction, distribution or commercial use.

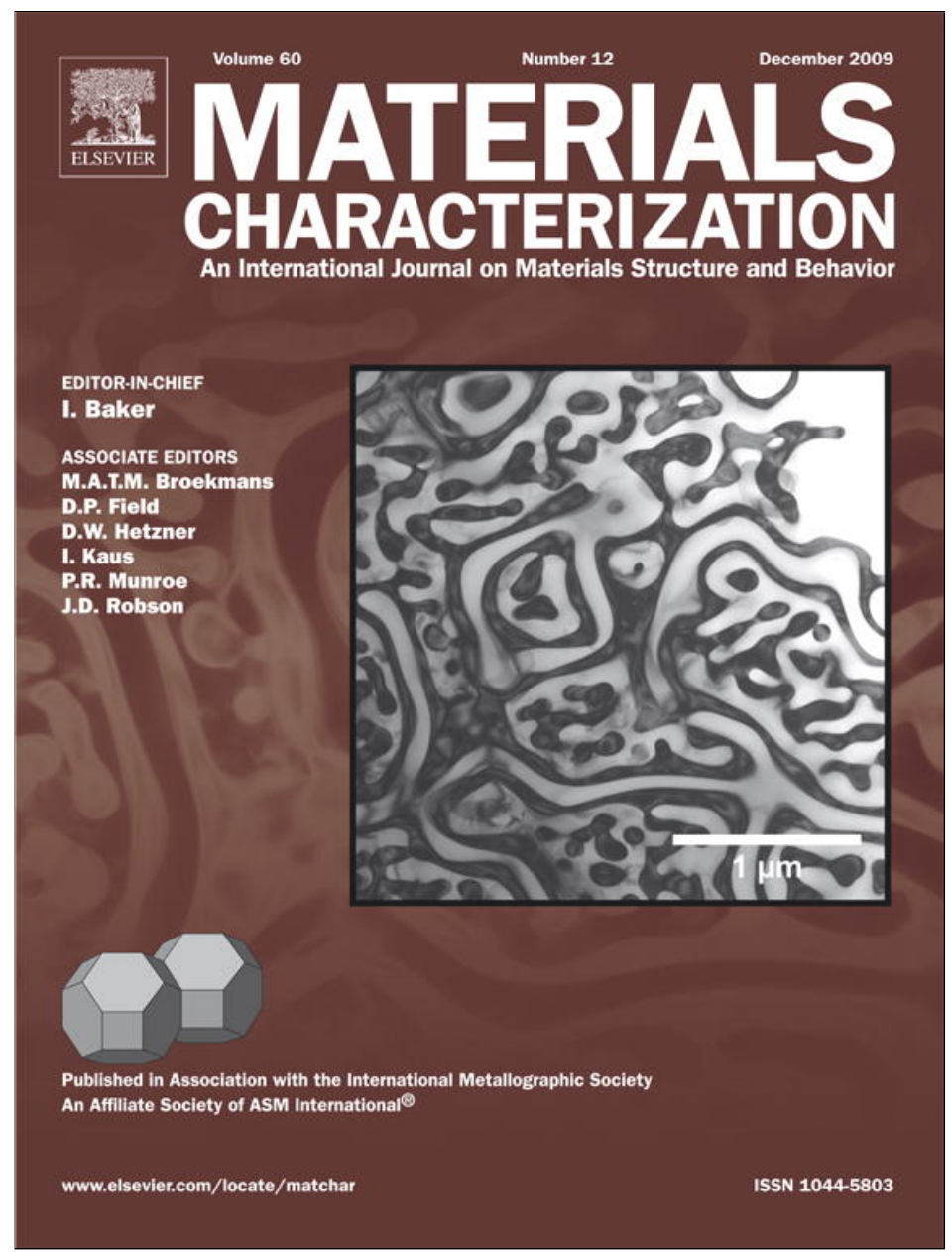

This article appeared in a journal published by Elsevier. The attached copy is furnished to the author for internal non-commercial research and education use, including for instruction at the authors institution and sharing with colleagues.

Other uses, including reproduction and distribution, or selling or licensing copies, or posting to personal, institutional or third party websites are prohibited.

In most cases authors are permitted to post their version of the article (e.g. in Word or Tex form) to their personal website or institutional repository. Authors requiring further information regarding Elsevier's archiving and manuscript policies are encouraged to visit:

http://www.elsevier.com/copyright 


\title{
Effect of microstructure on micromechanical performance of dry cortical bone tissues
}

\author{
Ling Yin ${ }^{a, *}$, Sudharshan Venkatesan ${ }^{b}$, Shankar Kalyanasundaram ${ }^{b}$, Qing-Hua Qin \\ ${ }^{a}$ School of Engineering and Physical Sciences, James Cook University, Townsville, QLD 4811, Australia \\ ${ }^{b}$ Department of Engineering, Australian National University, Canberra, ACT 0200, Australia
}

\section{A R T I C L E D A T A}

\section{Article history:}

Received 11 March 2009

Received in revised form 27 May 2009

Accepted 26 June 2009

\section{Keywords:}

Dry cortical bone

Deformation

Microstructure

Microcracks

Microindentation

\begin{abstract}
A B S T R A C T
The mechanical properties of bone depend on composition and structure. Previous studies have focused on macroscopic fracture behavior of bone. In the present study, we performed microindentation studies to understand the deformation properties and microcrackmicrostructure interactions of dry cortical bone. Dry cortical bone tissues from lamb femurs were tested using Vickers indentation with loads of 0.245-9.8 N. We examined the effect of bone microstructure on deformation and crack propagation using scanning electron microscopy (SEM). The results showed the significant effect of cortical bone microstructure on indentation deformation and microcrack propagation. The indentation deformation of the dry cortical bone was basically plastic at any applied load with a pronounced viscoelastic recovery, in particular at lower loads. More microcracks up to a length of approximately $20 \mu \mathrm{m}$ occurred when the applied load was increased. At loads of $4.9 \mathrm{~N}$ and higher, most microcracks were found to develop from the boundaries of haversian canals, osteocyte lacunae and canaliculi. Some microcracks propagated from the parallel direction of the longitudinal interstitial lamellae. At loads $0.45 \mathrm{~N}$ and lower, no visible microcracks were observed.
\end{abstract}

() 2009 Elsevier Inc. All rights reserved.

\section{Introduction}

The mechanical properties of bone have been the focal point of extensive studies over the past decades [1-4]. Knowledge of the mechanical properties of bone would help the clinical treatment of bone-related diseases associated with a reduction of bone strength and an increase in bone fracture [4-8]. Although significant progress has been made in biomechanical evaluation of bone, a complete understanding of bone mechanical properties remains to be developed [9-11]. Most previous biomechanical tests on bone have focused on macroscopic fracture based on structural characterization [3]. The outcomes lack the visualization of submicroscopic damage [3]. As a biological material, bone exhibits a complex microstructure and microcomponents, which result in complicated mechanical properties [12-18]. Recently, these properties have begun to be addressed quantitatively with regard to the microstructure of the tissue [11,12]. Microscopic damage in bone was found to contribute in a significant manner to an increase in bone fragility, leading to complications such as osteoporotic and stress fractures [3]. Microcracks can affect the mechanical properties of bone, giving rise to a decrease in strength and stiffness, and a decrease in fracture resistance. The accumulation of such damage may occur due to normal daily activities. For example, several studies have related fatigue or cyclic loading to microcrack formation $[3,6,8]$.

\footnotetext{
* Corresponding author. School of Engineering and Physical Sciences, James Cook University, Townsville, QLD 4811, Australia. Tel.: +61 7 47816254 .

E-mail address: ling.yin@jcu.edu.au (L. Yin).
} 
Cortical bone has a strongly hierarchical structure, in which there are phase and material direction changes over many length scales and a porosity of about $5 \%$ due to the presence of blood vessels and living cells [8]. These heterogeneities account for the ability of bones to contain stable cracks that can vary greatly in length. It is very difficult to determine at what level the processes leading to failure occur due to the complicated interactions between heterogeneities and microcracks when considering failure behavior [12]. The effects of microstructure of bone on crack propagation and mechanical properties need to be investigated [12].

Indentation tests represent a promising direction in characterizing the quality of bone repair as a function of location [3,19-22]. These tests have been used to measure local mechanical properties of callus and the surrounding tissues [23-25]. Hardness is the resistance of a material against deformation under indentation by an object. The advantage of hardness tests is that these tests can be done on very small specimens [3]. Microhardness is measured from the penetration of an indenter, which makes imprints of microscopic size, thus allowing the determination of hardness in small areas of the sample. Previous studies using microindentation mainly focused on microhardness anisotropy of compact bone [21-26] and hardness measurement of human enamel and dentine $[27,28]$.

Microindentation offers a means of characterizing the deformation properties of bone [19] and provides a basis for evaluating a range of contact-related properties, particularly surface-damage phenomena in sharp-particle compression [28]. Furthermore, imaging of micro-indented patterns using scanning electron microscopy can provide insight into the material response to mechanical loads at the micro scale to identify the role of microstructure of bone in damage. The aim of the present study was to investigate crack propagation and deformation behavior of dry cortical bone on a microscopic scale by means of microindentation. We examined the microcrack-microstructure interactions by evaluating indentation-induced cracks in osteons, interstitial lamellae, and woven fibrils using SEM. We measured the Vickers hardness during indentation using optical microscopy and recovered hardness using SEM. Micromechanistic damage in microindentation of dry cortical bone was identified.

\section{Experimental Procedures}

\subsection{Preparation of Bone Samples}

Three lamb femurs from 6 month old lambs, purchased from a local supermarket, were stored in a refrigerator at $-20{ }^{\circ} \mathrm{C}$. These femurs were macerated in a solution which contained $40 \mathrm{~g}$ Biozet laundry powder (KAO, Australia) and $2 \mathrm{l}$ water for 5 days at room temperature in a fume cupboard. Biozet laundry powder contains two types of enzymes for biological active cleaning, anionic and nonionic surfactant for lifting dirt from clothes, sodium perborate monohydrate for oxygen bleach, sodium alumino silicate for softening water, sodium carbonate for breaking up fatty soils, fluorescers for brightening fabric, soil suspending agent and perfume (KAO,
Australia). The $\mathrm{pH}$ value of the solution was 10.5. After 5 days, soft tissues were manually removed from the femurs using a rod, a cooking knife, and a brush.

Transverse-section samples of $10 \mathrm{~mm}$ thickness were cut from the central femurs using a diamond saw machine at a low rotary speed. Alcohol was utilized as coolant during the cutting process. The samples were washed to remove any residual abrasives from the cutting. Then, they were polished using metallographic polishing techniques. The initial polishing was performed on a series of silicon carbide papers of grit sizes of $60,40,15$, and $9 \mu \mathrm{m}$. Fine polishing was performed using diamond suspension slurries with grades $6,3,1$, and $0.25 \mu \mathrm{m}$ on polishing cloth. The samples were cleaned before proceeding to the next finer level of polishing. After the final polishing, the samples were stored in a fume cupboard at room temperature for two weeks.

\subsection{Standard Microhardness Indentation Testing}

The polished dry bone surfaces were indented with a Vickers diamond indenter in a microhardness tester (MHT-1, Matsuzawa Seiki, Japan) with an attached optical microscope. Prior to the length measurements, the optical microscope was calibrated retaining a relative system uncertainty of about $2 \%$. Five indentation loads of $0.245,0.49,1.96,4.9$ and $9.8 \mathrm{~N}$ were applied for $10 \mathrm{~s}$. Six indentations were made at each load on each transverse section. This resulted in a total of 30 indentations in each sample. A distance of at least two times the impression diagonal was kept between the indentations to prevent the interactions between neighboring indentations. The lengths of the indentation diagonals were measured with optical microscopy. Three samples were selected for repeat tests and production of total 18 indentations at each load. Analysis of variance (ANOVA) considering two-factor with replication at a 5\% significant level was applied for statistical analysis of hardness data.

The indented samples were carbon-coated and stored in an oven at $42{ }^{\circ} \mathrm{C}$ for $48 \mathrm{~h}$ for the purpose of being easily vacuumized in the SEM sample chamber. Samples were observed under an SEM (Cambridge 360, Cambridge, UK). Backscattered electron (BSE) imaging was performed at $20 \mathrm{kV}$ accelerating voltage at a working distance of $16 \mathrm{~mm}$, and 350 times and higher magnifications. The SEM was calibrated prior to the length measurements and had a relative system uncertainty of about $2 \%$. Analysis of variance (ANOVA) considering two-factor without replication at a $5 \%$ significant level was applied for comparison of hardness values measured using optical microscopy and SEM.

\section{Results}

The results of the indentation tests are shown in Table 1. Fig. 1 shows Vickers hardness against applied load. Each datum is the average with one standard deviation of 18 indentations in three samples. In particular, the hardness increased with the load at the low loads of $0.245 \mathrm{~N}$ and $0.49 \mathrm{~N}$. After the load reached $1.96 \mathrm{~N}$, hardness was independent of the load. By increasing the load from $0.245 \mathrm{~N}$ to $4.9 \mathrm{~N}$, hardness increased 


\begin{tabular}{lccccc}
\multicolumn{5}{l}{ Table 1 - Hardness data sheet (GPa). } \\
Sample & $9.8 \mathrm{~N}$ & $4.9 \mathrm{~N}$ & $1.96 \mathrm{~N}$ & $0.49 \mathrm{~N}$ & $0.245 \mathrm{~N}$ \\
\hline 1 & 0.51 & 0.60 & 0.44 & 0.54 & 0.44 \\
& 0.50 & 0.61 & 0.56 & 0.54 & 0.41 \\
& 0.57 & 0.59 & 0.56 & 0.51 & 0.46 \\
& 0.63 & 0.58 & 0.58 & 0.41 & 0.49 \\
& 0.57 & 0.54 & 0.56 & 0.54 & 0.49 \\
& 0.61 & 0.49 & 0.59 & 0.45 & 0.46 \\
2 & 0.51 & 0.46 & 0.50 & 0.51 & 0.44 \\
& 0.49 & 0.52 & 0.58 & 0.49 & 0.44 \\
& 0.50 & 0.48 & 0.53 & 0.51 & 0.41 \\
& 0.49 & 0.51 & 0.50 & 0.49 & 0.44 \\
& 0.50 & 0.53 & 0.49 & 0.54 & 0.41 \\
& 0.50 & 0.51 & 0.48 & 0.54 & 0.46 \\
3 & 0.53 & 0.53 & 0.48 & 0.54 & 0.46 \\
& 0.51 & 0.49 & 0.51 & 0.51 & 0.46 \\
& 0.50 & 0.55 & 0.51 & 0.54 & 0.41 \\
& 0.54 & 0.54 & 0.53 & 0.49 & 0.46 \\
& 0.55 & 0.56 & 0.53 & 0.54 & 0.41 \\
& 0.55 & 0.54 & 0.51 & 0.51 & 0.44 \\
\hline
\end{tabular}

by $15 \%$ from a mean of $0.45 \mathrm{GPa}$ to $0.54 \mathrm{GPa}$, whilst hardness values remained approximately unchanged when the load was increased from $1.96 \mathrm{~N}$ to $9.8 \mathrm{~N}$. Table 2 shows a two-factor with replication ANOVA for the hardness data. It shows that there is a significant difference in hardness among the animals (ANOVA, $p<0.05$ ). The hardness values vary significantly with the applied loads (ANOVA, $p<0.05$ ). However, the interaction of the different samples and loads is insignificant ((ANOVA, $p>0.05)$.

Fig. 2 shows a series of backscattered electron (BSE) images of indentation patterns at the applied loads of 9.8, 4.9, 1.96, 0.45 and $0.245 \mathrm{~N}$ at 350 times magnification. No large cracks are observed on the indentations patterns at any applied load. Plastic deformation is observed in all the indented areas. However, the indentation patterns were found to be apparently smaller by measuring the indentation diagonals under the SEM than the initial hardness indentation measured using optical microscopy immediately after the indentations were made. Fig. 3 shows the recovered Vickers hardness values calculated from SEM measurements compared with the initial values measured immediately after indentation in the hard-

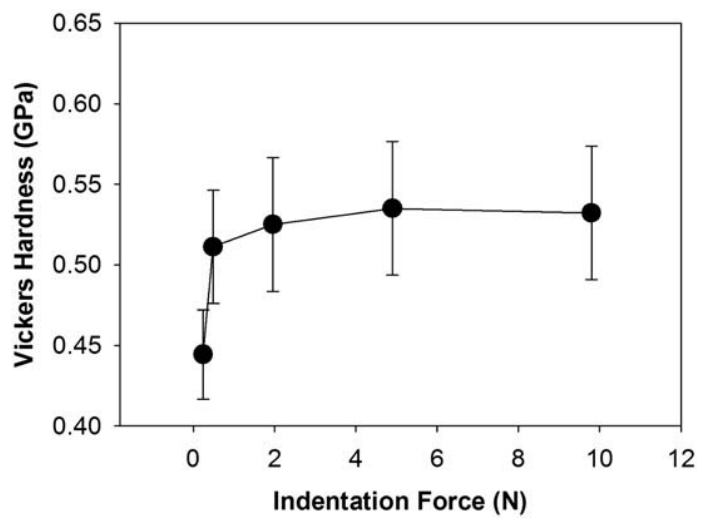

Fig. 1 - Vickers hardness of dry bone (lamb femurs). Each point is the average with the error bar of \pm one standard deviation of 18 indentations in three samples.
Table 2 - A two-factor with replication ANOVA for the data in Table 1.

\begin{tabular}{|c|c|c|c|c|c|c|}
\hline Summary & 9.8 & 4.9 & 1.96 & 0.49 & 0.245 & Total \\
\hline \multicolumn{7}{|l|}{1} \\
\hline Count & 6 & 6 & 6 & 6 & 6 & 30 \\
\hline Sum & 3.3933 & 3.4063 & 3.3045 & 2.9878 & 2.7607 & 15.8525 \\
\hline Average & 0.5655 & 0.5677 & 0.5507 & $7 \quad 0.4980$ & 0.4601 & 0.5284 \\
\hline Variance & 0.0028 & 0.0020 & 0.0031 & $1 \quad 0.0030$ & 0.0011 & 0.0039 \\
\hline \multicolumn{7}{|l|}{2} \\
\hline Count & 6.0000 & 6.0000 & 6.0000 & 6.0000 & 6.0000 & 30.0000 \\
\hline Sum & 2.9955 & 3.0090 & 3.0767 & 3.0831 & 2.5917 & 14.7559 \\
\hline Average & 0.4993 & 0.5015 & 0.5128 & $8 \quad 0.5138$ & 0.4319 & 0.4919 \\
\hline Variance & 0.0001 & 0.0006 & 0.0013 & $\begin{array}{ll}3 & 0.0005\end{array}$ & 0.0004 & 0.0014 \\
\hline \multicolumn{7}{|l|}{3} \\
\hline Count & 6.0000 & 6.0000 & 6.0000 & 6.0000 & 6.0000 & 30.0000 \\
\hline Sum & 3.1910 & 3.2156 & 3.0700 & $0 \quad 3.1309$ & 2.6470 & 15.2545 \\
\hline Average & 0.5318 & 0.5359 & 0.5117 & 0.5218 & 0.4412 & 0.5085 \\
\hline Variance & 0.0004 & 0.0006 & 0.0003 & 0.0004 & 0.0007 & 0.0016 \\
\hline \multicolumn{7}{|l|}{ Total } \\
\hline Count & 18.0000 & 18.0000 & 18.0000 & o 18.0000 & 18.0000 & \\
\hline Sum & 9.5798 & 9.6309 & 9.4512 & 9.2018 & 7.9994 & \\
\hline Average & 0.5322 & 0.5350 & 0.5251 & $1 \quad 0.5112$ & 0.4444 & \\
\hline Variance & 0.0017 & 0.0017 & 0.0017 & $7 \quad 0.0012$ & 0.0008 & \\
\hline \multicolumn{7}{|l|}{ ANOVA } \\
\hline $\begin{array}{l}\text { Source of } \\
\text { variation }\end{array}$ & SS & df & MS & $F$ & $p$-value & $F$ crit \\
\hline Sample & 0.0201 & 2.0000 & 0.0100 & 8.8371 & 0.0004 & 3.1186 \\
\hline Load & 0.1017 & 4.0000 & 0.0254 & 22.3604 & 0.0000 & 2.4937 \\
\hline Interaction & 0.0164 & 8.0000 & 0.0021 & 1.8064 & 0.0891 & 2.0644 \\
\hline Within & 0.0853 & 75.0000 & 0.0011 & & & \\
\hline Total & 0.2235 & 89.0000 & & & & \\
\hline
\end{tabular}

ness tester. Each recovered hardness datum is a single measurement with the SEM system error less than $2 \%$; the initial hardness datum is the average with one standard deviation of 18 indentations. The hardness values calculated after recovery were found not only to be significantly higher than the initial hardness mean value (ANOVA, $p<0.05$ ) but also significantly higher than the initial hardness mean value plus one standard deviation (ANOVA, $p<0.05$ ). In particular, at least $12 \%$ recovery of the indentation deformation occurred at loads lower than $0.45 \mathrm{~N}$, while at least $5 \%$ recovery of the deformed bone occurred at loads higher than $1.96 \mathrm{~N}$.

Fig. 2(a) and (b) show that at load $9.8 \mathrm{~N}$, the indented area covered several osteons, woven fibrils and interstitial lamellae. To reveal deformation details of the indentations, highmagnification BSE images are shown in Fig. 4. Fig. 4(a) demonstrates a microcrack propagated from a large haversian canal with a length of approximately $10 \mu \mathrm{m}$. It also shows that microcrack clusters developed from the boundaries of small osteocyte lacunae in the bone, with lengths smaller than $20 \mu \mathrm{m}$. Fig. 4(b) shows microcracks formed in the woven fibrils from a canaliculus, with lengths smaller than $5 \mu \mathrm{m}$. Fig. 4(c) reveals a microcrack developed at the apex of indentation along the longitudinal lamellae.

Fig. 5 shows high-magnification BSE images of indentation patterns indented at loads $4.9 \mathrm{~N}$ and $1.96 \mathrm{~N}$. These images show that deformed indentation areas cover both interstitial lamellar, woven, and osteonal structures. Fig. 5(a) clearly reveals a 

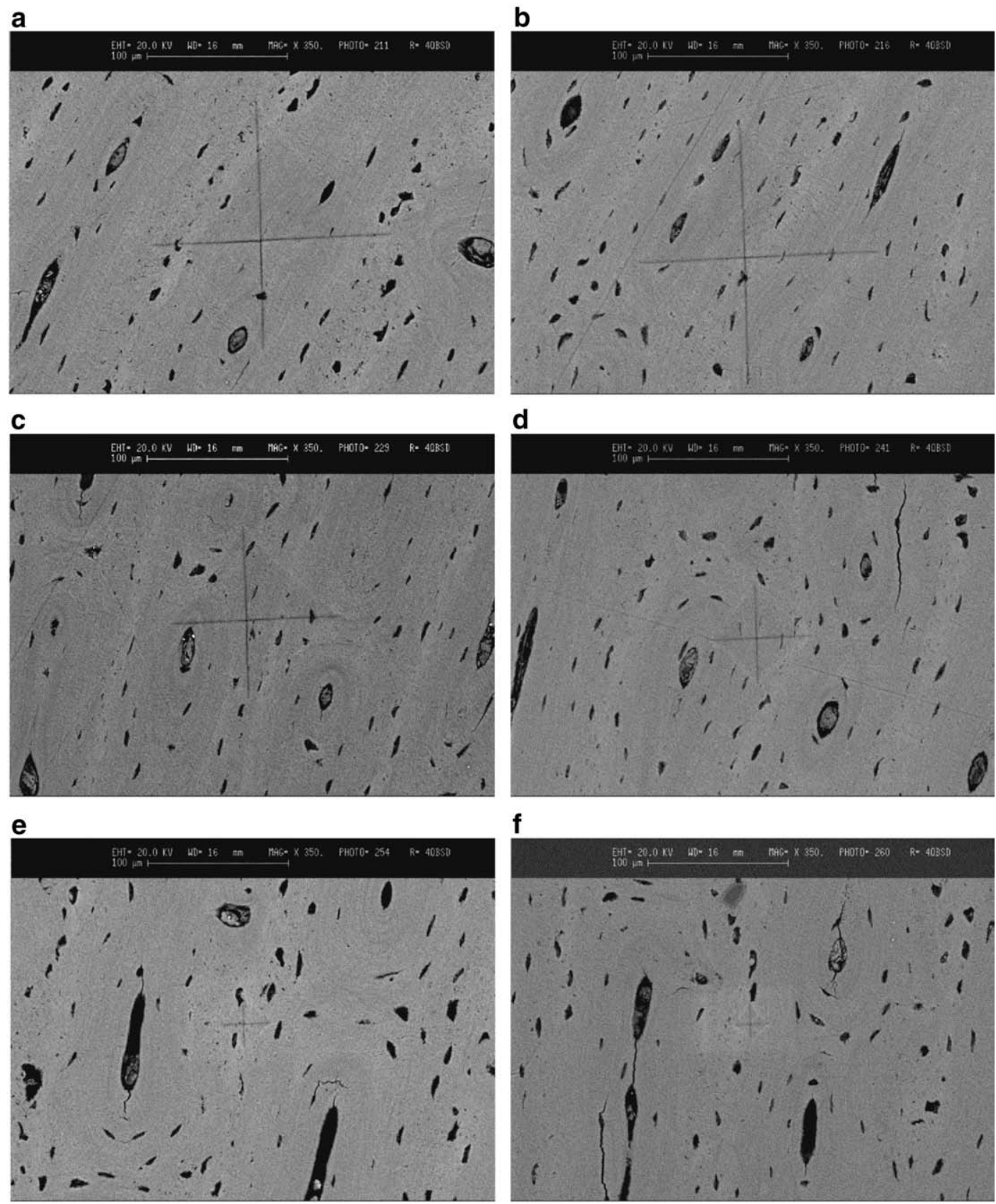

Fig. 2 - BSE images of the indentation patterns at loads (a) and (b) $9.8 \mathrm{~N}$, (c) $4.9 \mathrm{~N}$, (d) $1.96 \mathrm{~N}$, (e) $0.49 \mathrm{~N}$ and (f) $0.245 \mathrm{~N}$.

microcrack with a length of approximately $5 \mu \mathrm{m}$, propagated from a large haversian canal. Some microcracks developed from small osteocyte lacunae. Fig. 5 (b) demonstrates the microcracks propagated from the boundaries of canaliculi with lengths smaller than $10 \mu \mathrm{m}$. Fig. 5(c) and (d) show highmagnification BSE images of two indentation patterns indented at load $1.96 \mathrm{~N}$. Microcracks are seen to develop from the boundaries of canaliculi, all with lengths smaller than $5 \mu \mathrm{m}$.

Fig. 6 shows a high-magnification BSE image of the indentation patterns indented at loads $0.49 \mathrm{~N}$ and $0.245 \mathrm{~N}$, respectively. At load of $0.49 \mathrm{~N}$, no microcracks could be found to initiate from the boundaries of canaliculi, as shown in Fig. 6 (a). At load $0.245 \mathrm{~N}$, the indentation deformation is plastic without visible microcracks, as shown in Fig. 6(b).

\section{Discussion}

Bone is composed of approximately $60 \%$ ceramic nanoparticles (inorganic carbonated hydroxyapatite), 10\% water and about $30 \%$ fibrous polymer matrix (organic protein phase, composed of staggered tropocollagen molecules) by weight [3]. The bone microstructure exhibits a significant effect on the mode of deformation and crack propagation. In microindentation, the dry cortical bone has plastic, viscoelastic and brittle behaviors.

Previous studies have shown that staggered tropocollagen molecules are often able to dissipate energy by viscoplastic flow or formation of non-connected microcracks $[13,15]$. The organic matrix of bone as well as its function in the microstructure could 


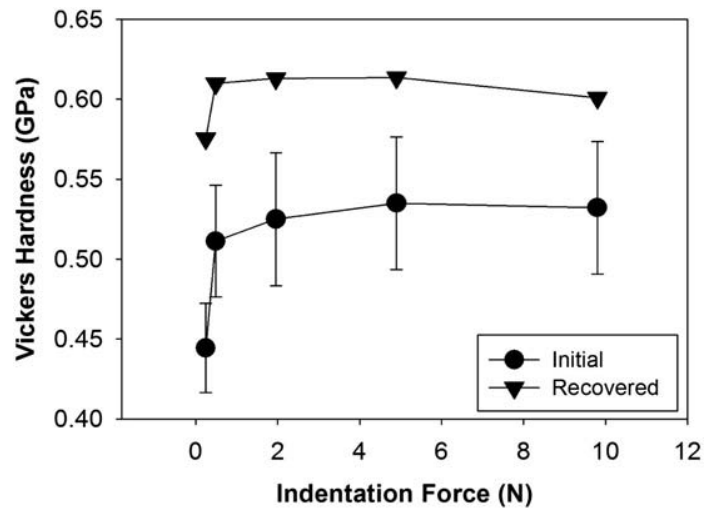

Fig. 3 - Recovered Vickers hardness measured under an SEM compared with the initial measurement shown in Fig. 1. Note that the recovered hardness datum is a single measurement with the SEM system error less than $2 \%$; the initial hardness datum is the average with the error bar of \pm one standard deviation of 18 indentations.

be the key to resist the separation of mineralized collagen fibrils [16]. Furthermore, a combination of molecular dynamics simulation and theoretical analysis proves that the characteristic nanostructure of mineralized collagen fibrils is vital for its high strength and its ability to sustain large deformation, as is relevant to the physiological role of bone [29]. The particular staggered structure of mineralized collagen fibrils contributes to toughening by providing an effective energy dissipation mechanism $[29,30]$. The plastic indentation behavior observed in this investigation is in agreement of the findings in cortical bone of different species [31].

In ceramics, well-known toughening mechanisms are based on crack ligament bridging and crack deflection [19]. In microindentation, all these phenomena were identified in the dry cortical bone. It is of interest to compare the microstructural responses to microindentation between the cortical bone and dental enamel, both of which are considered as hard tissues. Enamel contains $92-96 \%$ of inorganic hydroxyapatite, $1-2 \%$ of organic materials and 3-4\% of water by weight [32]. Due to the high percentage of ceramic hydroxyapatite, enamel was revealed to be extremely brittle in microindentation with extensive edge chipping and cracks [28] while cortical bone revealed not only plastic deformation but also brittle fracture depending on the local microstructures indented and applied loads.

Porosity from blood vessels in the cortical bone exhibited a significant effect on microcracks. At loads $4.9 \mathrm{~N}$ and higher, the observed anisotropic cracking behavior can be attributed to the weak boundaries of porosities (haversian canals, osteocyte lacunae and canaliculi), in particular, the larger pore boundaries formed from the large haversian canals. The microcracks developed more easily in the direction of the long axis of the planar ellipses of a large-sized pore formed from a haversian canal, as shown in Fig. 4(a). The propagation of the microcracks also occurred perpendicular to the long axis of the planar ellipses of the medium-sized pores formed from osteocyte lacunae, as shown in Fig. 4(a). Furthermore, microcracks propagated from small-sized pores formed from canaliculi as shown in Fig. 4(b). Bone is a hierarchically structured composite. At the indentation apex, microcracks were easily developed along the lamellar layers

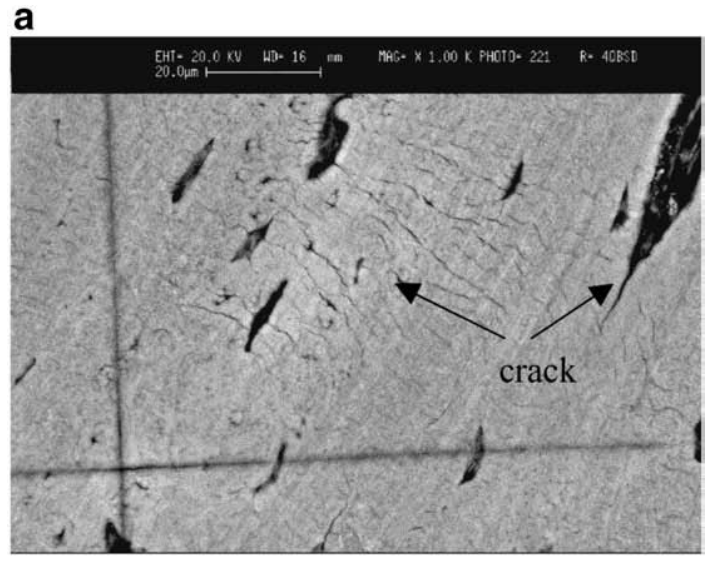

b

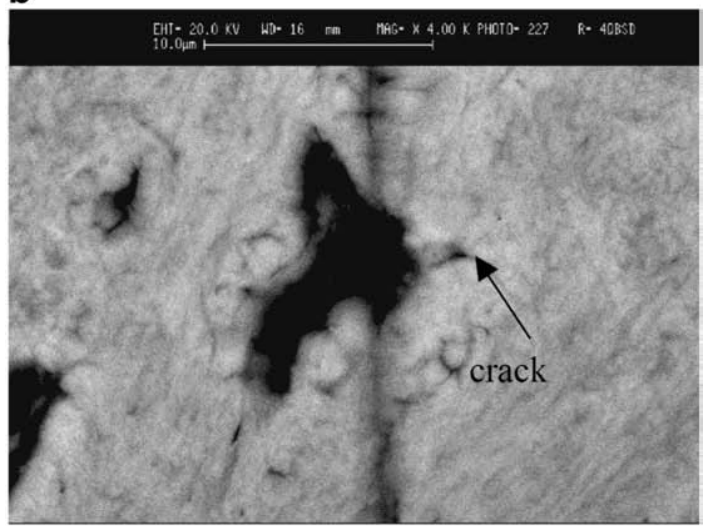

C

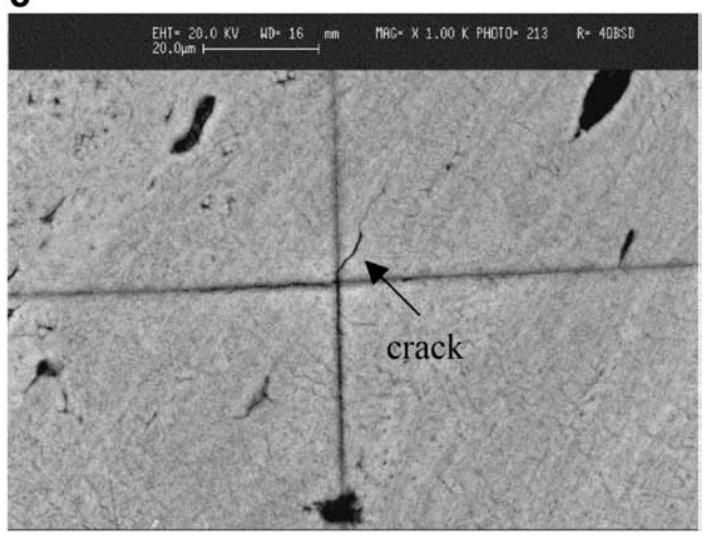

Fig. 4 - High-magnification BSE images of the indentation patterns at load $9.8 \mathrm{~N}$, showing (a) a microcrack propagated from a large haversian canal with a length of approximately $10 \mu \mathrm{m}$ and microcrack clusters developed from the boundaries of small osteocyte lacunae with lengths smaller than $20 \mu \mathrm{m}$, (b) microcracks formed in the woven fibrils from a canaliculus, with lengths smaller than $5 \mu \mathrm{m}$, and (c) a microcrack developed at the apex of indentation along the longitudinal lamellae.

as shown in Fig. 4(c). At loads smaller than $1.96 \mathrm{~N}$, indentation patterns were more plastic than brittle, in which cases the microcracks became smaller or were not observed.

Another direct observation is the significant recovery of indentation deformation as shown in Fig. 3. In particular, at 
a

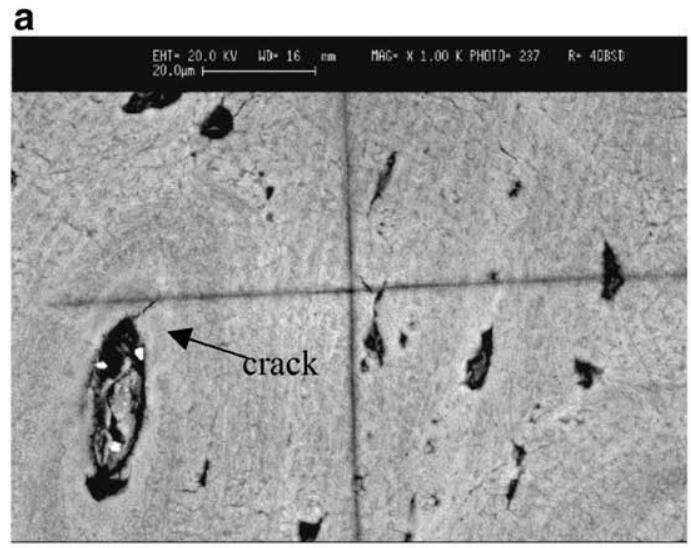

C

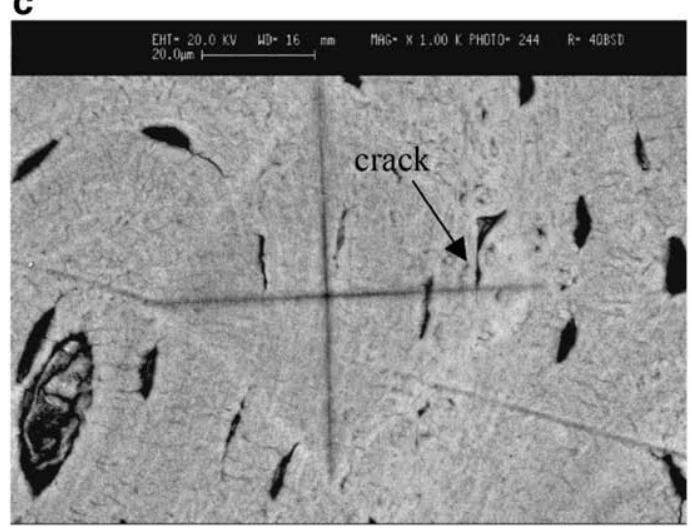

b

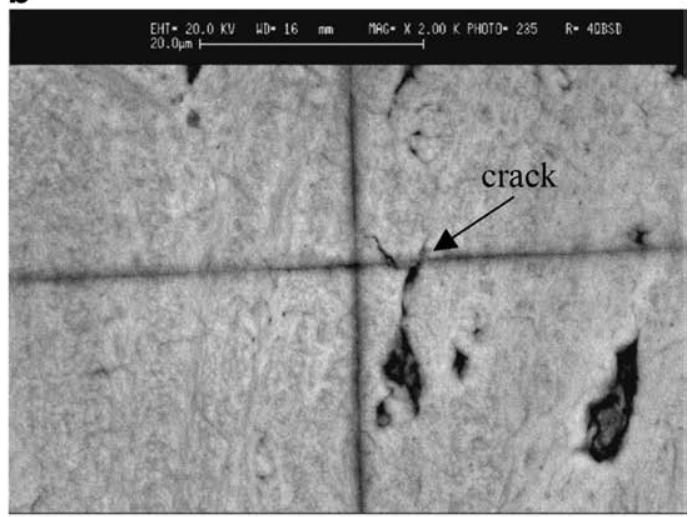

d

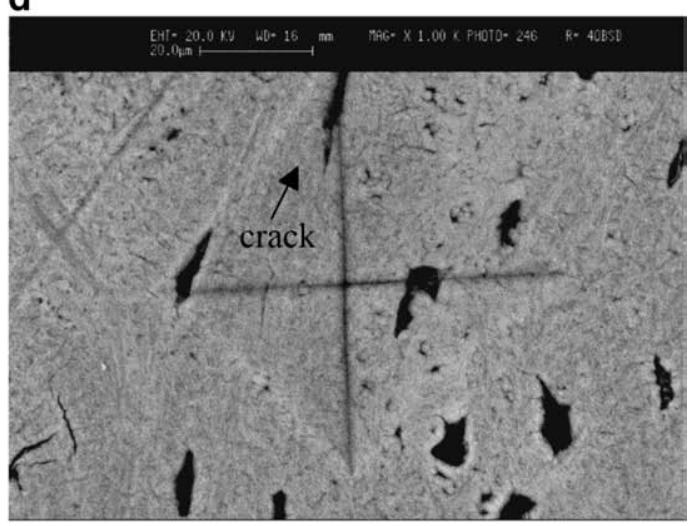

Fig. 5 - High-magnification BSE images of the indentation patterns at load $4.9 \mathrm{~N}$, showing (a) microcrack with a length of approximately $5 \mu \mathrm{m}$ propagated from a large haversian canal and some microcracks developed from small osteocyte lacunae, (b) microcracks propagated from the boundaries of canaliculi with lengths smaller than $10 \mu \mathrm{m}$; (c) and (d) two indentation patterns at load $1.96 \mathrm{~N}$ showing microcracks developed from the boundaries of canaliculi with lengths smaller than $5 \mu \mathrm{m}$.

loads below $0.45 \mathrm{~N}$, the bone exhibited more viscoelasticity than that at high loads. Bone recovery following microindentation was also observed in wet bovine femur [33]. This time dependence of viscoelasticity in bone was observed in R-curve testing of human cortical bone as well [11]. Time-dependent crack growth occurred in bone under sustained (non-cyclic) in vitro loads at stress intensities lower than the nominal crackinitiation toughness [11]. Effects of viscoelasticity and timedependent plasticity of human cortical bone were further investigated using nanoindentation [34]. However, the exact nature of this behavior is still unclear [11].

The bone hardness increases with load, as shown in Fig. 1. This phenomenon was also observed in microindentation of dry embalmed human rib [26]. The hardness values of the dry human rib were found to differ slightly from portion to portion of the skeleton [26]. A pile-up of material near the corners of the pyramidal indents was found due to the applied stress of indentation [26]. However, in microindentation of wet bovine metacarpus, hardness decreased with the applied load [21]. No discernable material pile-up at the residual impression edges was observed [21]. For engineering materials such as ceramics or metals, hardness versus load is either constant or decreasing with load or shows an abrupt transition to a constant value [35]. The similarity and difference of hardness-load relations between dry and wet bone tissues can be possibly attributed to water in bone tissue. The percent of water in bone tissue is an important contributor to bone strength [36]. However, the role of water in the mechanics of bone remains largely mysterious [4].

Research has found that for natural materials, the widely used engineering concept of stress concentration at flaws is no longer valid due to their many levels of hierarchical structures [14]. It should be noted that at the microscopic level, bone has a cylindrical microstructure formed by the haversian systems. Because of this, comparisons of hardness values at different length scales should be made with extreme caution. Small features of deformation on the scale of the distance between osteocytes versus hardness values and the scale of large features of multiple osteons might be different. In this investigation, the indented patterns of microscopic sizes on the bone samples had average diagonals of the indentations in the range $30-200 \mu \mathrm{m}$ at loads $0.245-9.8 \mathrm{~N}$. At the highest load of $9.8 \mathrm{~N}$, the indented patterns, as shown in Fig. 2, partially covered several osteons. At lower loads, the indented patterns could only cover a small area of an osteon. At low-level loads, nanoindentation might be a better means for mechanical testing of bone. The published work on nanoindentation of trabecular and interstitial lamellae in osteons indicates that hardness and modulus were different among the various microstructural components $[37,38]$. These differences were 


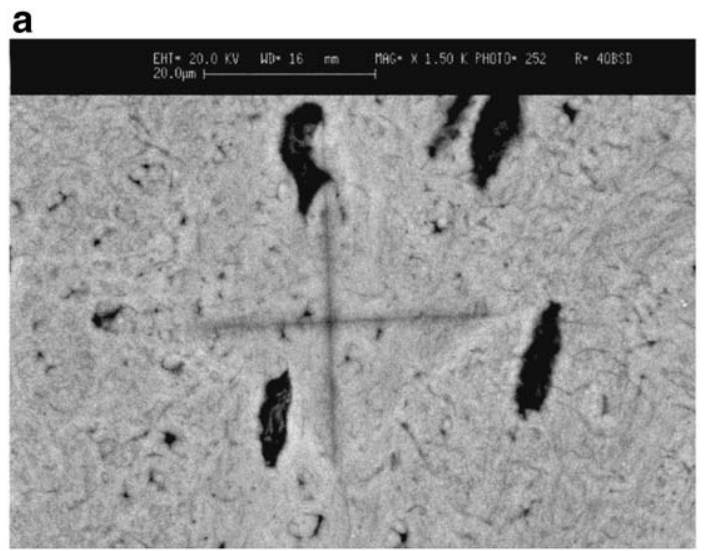

b

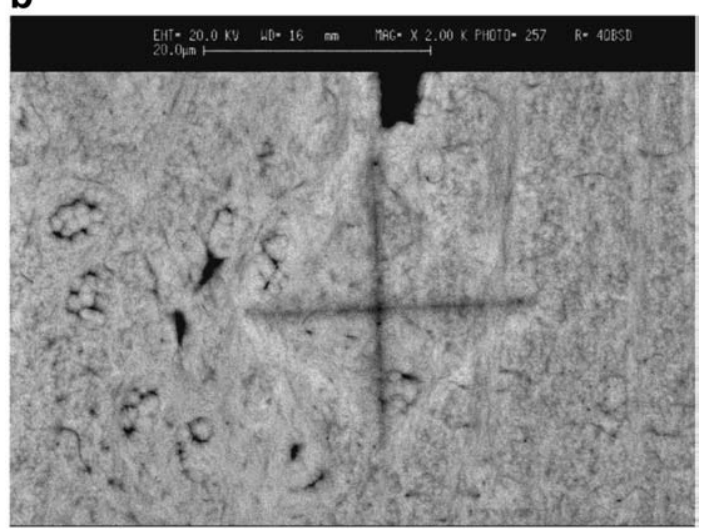

Fig. 6 - (a) High-magnification BSE image of the indentation pattern at load $0.45 \mathrm{~N}$, showing plastic deformation and little microcracks from the boundaries of canaliculi, and (b) the indentation pattern at load $0.245 \mathrm{~N}$, showing plastic deformation without visible microcracks in the indented area.

attributed to collagen fibril orientation and anisotropy as well as variation in mineral content [13]

With currently available optical imaging techniques, it is very difficult to examine microcracks in biological materials such as bone. Scanning electron microscopy provides highresolution images at the cost of dehydration of samples. Confocal laser scanning microscopy enables to observe wet bone tissues suffering from limited resolutions [39,40]. Efforts need to be made for high-quality imaging of biological materials in their natural states. So far no rigorous structure-property relationship exists for bone. This could be due to the complex hierarchical structure of bone with multiple levels of hierarchies, each of which as characteristic mechanical properties, deformation and toughening mechanisms.

\section{Conclusions}

We have conducted micromechanical testing of dry cortical bone tissues (lamb femurs) on a microscopic scale with a Vickers indenter. We have found that the complicated mechanical behaviors of the dry cortical bone tissues were highly dependent on microstructural features. The mechanism underlying cortical bone properties of plasticity, viscoe- lasticity and brittleness depended upon the applied load, i.e., some brittle behavior at higher loads and a higher percentage of viscoelastic recovery at lower loads. Indentation-induced microcracks were observed to strongly interact with pores in osteons formed from haversian canals, osteocyte lacunae, and canaliculi and lamellar layers. Vickers hardness revealed time-dependent and load-dependent behaviors.

\section{Acknowledgments}

This work was supported by the Australian Research Council Discovery Project Grant No. DP0665941. The authors would like to thank Zbigniew Stachurski and Anthony Flynn of the Australian National University (ANU) for valuable discussions. They are also grateful to Frank Brink, Cheng Huang, Geoffrey Hunter and Daryl Webb of ANU Electron Microscope Unit for experimental assistance.

\section{R E F E R E N C E S}

[1] Robling AG, Castillo AB, Turner CH. Biomechanical and molecular regulation of bone remodeling. Annu Rev Biomed Eng 2006;8:455-98.

[2] Liebschner MAK. Biomechanical consideration of animal models used in tissue engineering of bone. Biomaterials 2004;25:1697-714.

[3] Athanasiou KA, Zhu C-F, Lanctot DR, Agrawal CM, Wang X. Fundamentals of biomechanism in tissue engineering of bone. Tissue Eng 2003;6:361-81.

[4] Buehler MJ. Nano- and micromechanical properties of hierarchical biological materials and tissues. J Mater Sci 2007;42:8765-70.

[5] Roy ME, Rho J-Y, Tsui TY, Evans ND, Pharr GM. Mechanical and morphological variation of the human lumbar vertical cortical and trabecular bone. J Biomed Mater Res 1999;44:191-7.

[6] Augat P, Schorlemmer S. The role of cortical bone and its microstructure in bone strength. Age Ageing 2006;35-S2:ii27-31.

[7] Currey JD. Bones: Structure and Mechanics. New Jersey: Princeton University Press; 2002.

[8] Taylor D, Hazenberg JG, Lee TC. Living with cracks: damage and repair in human bone. Nat Maters 2007;6:263-8.

[9] Hoc T, Henry L, Verdier M, Aubry D, Sedel L, Meunier A. Effect of microstructure on the mechanical properties of haversian cortical bone. Bone 2006;38:466-74.

[10] Mullins LP, Bruzzi MS, McHugh PE. Measurement of the microstructural fracture toughness of cortical bone using indentation fracture. J Biomech 2007;40:3285-8.

[11] Nalla RK, Kruzic JJ, Kinney JH, Ritchie RO. Mechanistic aspects of fracture and R-curve behavior in human cortical bone. Biomaterials 2005;26:217-31.

[12] Nalla RK, Kinney JH, Ritchie RO. Mechanistic fracture criteria for the failure of human cortical bone. Nat Maters 2003;2:164-8.

[13] Tai K, Dao M, Suresh S, Palazoglu A, Oritiz C. Nanoscale heterogeneity promotes energy dissipation in bone. Nat Maters 2007;6:454-62.

[14] Gao H, Ji B, Jäger IL, Arzt E, Fratzl P. Materials become insensitive to flaws at nanoscale: lessons from nature. PNAS 2003;100:5597-600.

[15] Peterlik H, Roschger P, Klaushifer K, Fratzl P. From brittle to ductile fracture of bone. Nat Maters 2006;5:52-5. 
[16] Fantner GE, Hassenkam T, Kindt JH, Weaver JC, Birkedal H, Pechenik L, Cutron JA, Cidade GAG, Stucky GD, Morse DE, Hansma PK. Sacrificial bonds and hidden length dissipate energy as mineralized fibrils separate during bone fracture. Nat Maters 2005;4:612-6.

[17] Upta HS, Stachewicz U, Wagermaier W, Roschger P, Wagner HD, Fratzl P. Mechanical modulation at the lamellar level in osteonal bone. J Mater Res 2006;21:1913-21.

[18] Hassenkam T, Fantner GE, Cutroni JA, Weaver JC, Morse DE, Hansma PK. High-resolution AFM imaging of intact and fractured trabecular bone. Bone 2004;35:4-10.

[19] An YH, Draughn RA. Mechanical Testing of Bone and the Bone-Implant Interface. Florida: CRC Press; 2000.

[20] Amanat N, He LH, Swain MV, Little DG. The effect of zoledronic acid on the intrinsic material properties of healing bone: an indentation study. Med Eng Phys 2008;30:843-7.

[21] Johnson WM, Rapoff AJ. Micro indentation in bone: hardness variation with five independent variables. J Mater Sci Mater Med 2007;18:591-7.

[22] Evans GP, Behiri JC, Currey DJ, Bonfield W. Microhardness and Young's modulus in cortical bone exhibiting a wide range of mineral volume fractions, and in a bone analogue. J Mater Sci Mater Med 1990;1:38-43.

[23] Riches PE, Everitt NM, Heggie AR, McNally DS. Microhardness anisotropy of lamellar bone. J Biomech 1997;30:1059-61.

[24] Mahoney E, Holt A, Swain M, Kilpatrick N. The hardness and modulus of elasticity of primary molar teeth: an ultra-micro-indentation study. J Dent 2000;28:589-94.

[25] Riches PE, Everitt NM, McNally DS. Knoop microhardness anisotropy of the ovine radius. J Biomech 2000;33:1551-7.

[26] Ramrakhiani M, Pal D, Murty T. Micro-indentation hardness studies on human bones. Acta Anat 1979;103:358-62.

[27] Meredith N, Sherriff M, Setchell DJ, Swanson SAV. Measurement of microhardness and Young's modulus of human enamel and dentine using an indentation technique. Arch Oral Biol 1996;41:539-45.
[28] Xu HHK, Smith DT, Jahanmir S, Romberg E, Kelly JR, Thompson VP, Rekow ED. Indentation damage and mechanical properties of human enamel and dentin. J Dent Res 1998;77:472-80.

[29] Buehler MJ. Molecular nanomechanics of nascent bone: fibrillar toughening by mineralization. Nanotechnology 2007;18:295102-200.

[30] Buehler MJ. Molecular architecture of collagen fibrils: a critical length scale for tough fibrils. Curr Appl Phys 2008;8:440-2.

[31] Fratzl P, Weinkamer R. Nature's hierarchical materials. Proc Mater Sci 2007;52:1263-334.

[32] Giannini M, Soares CJ, de Carvalho RM. Ultimate tensile strength of tooth structures. Dent Mater 2004;20:322-9.

[33] Everitt NM, Rajah S, McNally DS. Bone recovery following indentation. J Bone Jt Surg Br Vol 2006;88-B:398.

[34] Fan Z, Rho J-Y. Effects of viscoelasticity and time-dependent plasticity on nano-indentation measurements of human cortical bone. J Biomed Mater Res 2003;67A:208-14.

[35] Quinn JB, Quinn GD. Indentation of brittle of ceramics: a fresh approach. J Mater Sci 1997;32:4331-46.

[36] Hall SJ. Basic Biomechanics 4th Edition. New York: McGraw-Hill Higher Education; 2003.

[37] Rho JY, Tsui TY, Pharr GM. Elastic properties of human cortical and trabecular lamellar bone measured by nanoindentation. Biomaterials 1997;18:1325-30.

[38] Zysset PK, Guo XE, Hoffler CE, Moore KE, Goldstein SA. Elastic modulus and hardness of cortical and trabecular bone lamellae measured by nanoindentaiton in the human femur. J Biomech 1999;32:1005-12.

[39] Fazzalari NL, Forwood MR, Manthey RA, Smith K, KoLesik P. Three dimensional confocal images of microdamage in cancellous bone. Bone 1998;23:373-8.

[40] Yin L, Venkatesan S, Webb D, Kalyanasundaram S, Qin QH. Effect of cryo-induced microcracks on microindentation of hydrated cortical bone tissue. Mater Charact 2009; 60:783-91. 